\title{
A contaminant transport model for wetlands accounting for distinct residence time bimodality
}

\author{
T. Musner ${ }^{\mathrm{a}, *}$, A. Bottacin-Busolin ${ }^{\mathrm{b}}$, M. Zaramella ${ }^{\mathrm{a}}$, A. Marion ${ }^{\mathrm{a}}$ \\ ${ }^{a}$ Department of Industrial Engineering, University of Padua, via F. Marzolo 9, 35131 Padova, Italy \\ ${ }^{\mathrm{b}}$ School of Mechanical, Aerospace and Civil Engineering, University of Manchester, Manchester, M13 9PL, UK
}

\section{A R T I C L E I N F O}

\section{Article history:}

Received 29 November 2013

Received in revised form 8 April 2014

Accepted 16 April 2014

Available online 24 April 2014

This manuscript was handled by Peter $\mathrm{K}$

Kitanidis, Editor-in-Chief, with the

assistance of Christophe Darnault, Associate Editor

\section{Keywords:}

Wetland channelization

Vegetation density

Residence time distribution

One-dimensional model

Shallow water model

STIR-DTD

\begin{abstract}
S U M M A R Y
Vegetation plays a major role in controlling the fate of contaminants in natural and constructed wetlands. Estimating the efficiency of contaminant removal of a wetland requires separate knowledge of the residence time statistics in the main flow channels, where the flow velocity is relatively higher, and in the more densely vegetated zones, where the velocity is smaller and most of the biochemical transformations occur. A conceptual wetland characterized by a main flow channel (MFC) and lateral vegetated zones (LVZs) is modeled here using a two-dimensional depth-averaged hydrodynamic and advectiondispersion model. The effect of vegetation is described as a flow resistance represented in the hydrodynamic model as a function of the stem density. Simulations are performed for a given flow discharge and for increasing values of the ratio between the vegetation density in the LVZs and in the MFC. Residence time distributions (RTDs) of a nonreactive tracer are derived from numerical simulations of the solute breakthrough curves (BTCs) resulting from a continuous concentration input. Results show that increasing vegetation densities produce an increasingly pronounced bimodality of the RTDs. At longer times, the RTDs decrease exponentially, with different timescales depending on the stem density ratio and other system parameters. The overall residence time distribution can be decomposed into a first component associated with the relatively fast transport in the MFC, and a second component associated with the slower transport in the LVZs. The weight of each temporal component is related to the exchange flux at the MFC-LVZ interface. A one-dimensional transport model is proposed that is capable to reproduce the RTDs predicted by the depth-averaged model, and the relationship between model and system parameters is investigated using a combination of direct and inverse modeling approaches.
\end{abstract}

(c) 2014 Elsevier B.V. All rights reserved.

\section{Introduction}

The removal efficiency of natural and constructed wetlands is controlled by the time spent by contaminants in the vegetated zones (Persson et al., 1999). Vegetation plays an important role for two main reasons: firstly, dense vegetated zones locally decrease the flow velocity, creating stagnant zones and favoring the sedimentation of suspended solids; secondly, plant roots and associated epiphytic biofilms are responsible for the transformation of the transported substances as a result of biochemical processes. The combined effect of vegetation and wetland topography can also produce hydraulic shortcuts that negatively affects the wetland performance.

\footnotetext{
* Corresponding author.

E-mail addresses: tommaso.musner@gmail.com (T. Musner), andrea.bottacin busolin@manchester.ac.uk (A. Bottacin-Busolin), mattia.zaramella@gmail.com (M. Zaramella), andrea.marion@unipd.it (A. Marion).
}

Despite their typical heterogeneity, constructed wetlands for waste water treatment are often designed with reference to an average water residence time (Kadlec and Wallace, 2009), which can lead to significant inaccuracies in the evaluation of their performance (Kadlec, 2000). Zero-dimensional models are often used because of their simplicity, but they are inadequate to represent complex spatial patterns resulting from heterogeneous vegetation distributions (Akratos and Tsihrintzis, 2007; Kadlec and Wallace, 2009). One-dimensional transient storage models have been widely used to represent the transport and retention dynamics in rivers due to vegetation and permeable beds (Runkel and Broshears, 1991; Bencala and Walters, 1983; Gooseff et al., 2003), but a major question is whether these models can represent the more complex hydrodynamics found in natural and constructed wetlands. Recent studies (Keefe et al., 2004; Martinez and Wise, 2003) have used transient storage models to assess the contaminant removal in constructed wetlands, providing in some cases good approximations of the breakthrough curves (BTCs). However, 
these models fail to describe in general the different flow paths through vegetation and the main flow channels, which can result in a clear bimodality of the solute breakthrough curves. A bimodal behavior of the hydraulic residence time distributions (RTDs) induced by riparian vegetation has been experimentally observed in a real wetland by Martinez and Wise (2003) and in a conceptualized lowland river by Perucca et al. (2009).

Since spatial heterogeneity plays a fundamental role in controlling the fate of contaminants, a two-dimensional approach is more appropriate to describe transport dynamics in wetlands. Although two-dimensional hydrodynamic models have already been used in the past (Persson et al., 1999; Somes et al., 1999), the formulation of more detailed models accounting for vegetation distribution is relatively recent (Arega and Sanders, 2004; Jenkins and Greenway, 2005), yet none of the suggested models provides a clear relationship between vegetation density and hydraulic RTDs. This relationship is investigated in the present study as a function of the degree of flow channelization of a wetland induced by vegetation. To this end, a two-dimensional depth-averaged flow and solute transport model is applied to a conceptual wetland characterized by a central main flow channel (MFC) and lateral vegetated zones (LVZs), and simulations are performed for different vegetation densities. A one-dimensional transport model is also proposed and calibrated against the RTDs derived from the two-dimensional depth-averaged model. The behavior of the model parameters is analyzed as a function of the system parameters and analytical relationships are provided for the average residence times and flow discharges in the MFC and in the LVZs.

\section{2-D depth-averaged model}

Assuming that the vertical gradients are small compared to the horizontal gradients, the transport of a dissolved contaminant in a wetland can be represented by a two-dimensional depth-averaged model. This assumption has often been used in wetland studies (Somes et al., 1999; Arega and Sanders, 2004; Jenkins and Greenway, 2005) and is consistent with the simplified wetland topography and geometry analyzed in this work. It is further assumed that the long-term, average performance of a wetland can be represented by steady state flow conditions. This representation can also be useful to describe gradually unsteady flows, for which variations can be represented as a sequence of steady states.

\subsection{Hydrodynamic model}

Under the assumption of hydrostatic pressure, steady-state flow, negligible wind and Coriolis forces, the depth-averaged velocity field and water depth satisfy the following equations ( $\mathrm{Wu}$, 2007):

$$
\begin{aligned}
& \frac{\partial(h U)}{\partial x}+\frac{\partial(h V)}{\partial y}=0 \\
& \frac{\partial\left(h U^{2}\right)}{\partial x}+\frac{\partial(h U V)}{\partial y}=-g h \frac{\partial z_{s}}{\partial x}-\frac{\tau_{b x}}{\rho}-\frac{\tau_{v x}}{\rho} \\
& \frac{\partial(h U V)}{\partial x}+\frac{\partial\left(h V^{2}\right)}{\partial y}=-g h \frac{\partial z_{s}}{\partial y}-\frac{\tau_{b y}}{\rho}-\frac{\tau_{v y}}{\rho}
\end{aligned}
$$

The quantities $U$ and $V$ represent the depth-averaged velocities $\left(\mathrm{m} \mathrm{s}^{-1}\right)$ in the $x$ - and $y$-directions, respectively, $h$ is the water depth, $z_{s}$ is the water surface elevation $(\mathrm{m})$, and $\rho$ the water density $\left(\mathrm{kg} \mathrm{m}^{-3}\right)$. The shear stresses $\tau_{b x}$ and $\tau_{b y}$ account for bed resistance, whereas $\tau_{v x}$ and $\tau_{v y}$ account for vegetation resistance along the $x$ - and $y$-direction, respectively. Eqs. (2) and (3) assume that Reynolds stresses are negligible compared to bed and vegetative resistance. In channelized wetlands, Babarutsi et al. (1989) experimentally showed that bed friction dominates and Reynolds stresses can be neglected when $c_{b D} L_{h} / h>0.1$, where $L_{h}$ is the horizontal length scale of recirculation zones, and $c_{b D}$ is the bed drag coefficient. Since typical values of $c_{b D}$ vary between 0.009 and 0.003 in tidal wetlands, this model is expected to resolve recirculation zones where $L_{h} / h>10$ 30 (Arega and Sanders, 2004).

The contribution of bed friction to bed shear stresses is computed by adapting the one-dimensional relationships proposed by Kadlec (1990) to a two-dimensional velocity field, which leads to:

$$
\begin{gathered}
\tau_{b x}=\rho c_{b D} U \sqrt{U^{2}+V^{2}} \\
\tau_{b y}=\rho c_{b D} V \sqrt{U^{2}+V^{2}}
\end{gathered}
$$

The bed drag coefficient $c_{b D}(-)$ in Eq. (4) combines both laminar and turbulent stresses, and can be calculated as follows (Kadlec, 1990):

$c_{b D}=\frac{3 v}{h \sqrt{U^{2}+V^{2}}}+f^{2} g h^{-1 / 3}=\frac{3}{R e_{h}}+f^{2} g h^{-1 / 3}$

where $v$ is the kinematic viscosity $\left(\mathrm{m}^{2} \mathrm{~s}^{-1}\right)$ and $f$ is the Manning's friction coefficient $\left(\mathrm{s}^{-1} \mathrm{~m}^{-1 / 3}\right)$. For depth-Reynolds numbers $R e_{h}$ less than 500 the first term on the right-hand side prevails, whereas the second term prevails for depth-Reynolds numbers greater than 12500 (Kadlec, 1990). The sum of the two terms therefore provides a complete description of the bed shear stresses for a wide range of depth-Reynolds numbers.

Vegetation drag is modeled in a similar way by representing aquatic plant stems as an array of randomly distributed cylinders with a uniform diameter $d(\mathrm{~m})$, as suggested by Kadlec (1990) and by Arega and Sanders (2004):

$$
\begin{aligned}
& \tau_{v x}=\frac{1}{2} \rho c_{v D} n l d U \sqrt{U^{2}+V^{2}} \\
& \tau_{v y}=\frac{1}{2} \rho c_{v D} n l d V \sqrt{U^{2}+V^{2}}
\end{aligned}
$$

where $n$ is the superficial stem density $\left(\mathrm{m}^{-2}\right), l$ is the submerged stem length $(\mathrm{m})$ and $c_{v \mathrm{D}}$ is the vegetation drag coefficient. For fully emergent vegetation, as considered in this work, the submerged stem length can be taken as the water depth. The behavior of the vegetation drag coefficient for an individual cylinder is well known (Bennett and Myers, 1962; White, 1991) and shows a decreasing trend for increasing stem Reynolds numbers, defined as $R e_{d}=\sqrt{U^{2}+V^{2}} d / v$. Other studies (Ergun, 1952; Petryk, 1969; Nepf, 1999; Hill et al., 2001; Blevins, 2005) have shown that neighboring cylinders can produce a velocity reduction and, as a consequence, a reduced drag (Tanino and Nepf, 2008). Nevertheless, cumulative effects of multiple wake interactions can be neglected for sufficiently sparse vegetation, i.e. when the solid volume fraction ad is lower than 0.1 (Raupach, 1992). Here, the parameter $a$ represents the plant area projected on a plane perpendicular to the flow direction per unit volume $\left(\mathrm{m}^{-1}\right)$, and can be written as a function of the superficial stem density, $a=n d$, if the plants are modeled as cylinders.

Nepf (1999) performed numerical and laboratory experiments for superficial stem densities lower than $2500 \mathrm{stems} / \mathrm{m}^{2}$ and a stem diameter of $2 \mathrm{~mm}$, corresponding to a solid volume fraction $a d=n d^{2} \approx 0.01$, and found relatively constant values of $c_{v D}$. Such values are common in natural and constructed wetlands. Tanner (2001) measured the superficial density of vegetation in pilot-scale constructed wetlands and found $1400-1500$ stems $/ \mathrm{m}^{2}$ of Schoenoplectus Tabernaemontani and densities higher than $2000 \mathrm{stems} / \mathrm{m}^{2}$ of Schoenoplectus Validus. Hocking (1989) and Parr (1990) found superficial vegetation densities of Phragmites Australis ranging from 70 to 250 stems $/ \mathrm{m}^{2}$. Other hydraulic studies on diffusion in 
emergent vegetation (Nepf et al., 1997) and vegetation drag (Hall and Freeman, 1994) used densities ranging between 200-2000 stems $/ \mathrm{m}^{2}$ and $400-800 \mathrm{stems} / \mathrm{m}^{2}$. In this study, a vegetation density in the range between 50 and 800 stems $/ \mathrm{m}^{2}$ is considered, for which the vegetation drag coefficient depends only on the stem Reynolds number, $R e_{d}$. A continuous range of $R e_{d}$ was modeled using the relationship proposed by Kadlec (1990). This relationship is based on laboratory tests performed by Wieselberger (1921) for laminar flows, and Tritton (1959) for turbulent flows. Kadlec's formulation, similar to the one proposed by White (1991), is given as follows:

$c_{v D}=\frac{10 \mu}{\rho d \sqrt{U^{2}+V^{2}}}+1=\frac{10}{R e_{d}}+1=\frac{10}{R e_{h}} \frac{h}{d}+1$

\subsection{Solute transport model}

Solute transport of a passive tracer through a wetland is simulated with a depth-averaged solute transport model,

$$
\begin{aligned}
\frac{\partial(h C)}{\partial t}+\frac{\partial(h U C)}{\partial x}+\frac{\partial(h V C)}{\partial y}= & \frac{\partial}{\partial x}\left(h E_{x x} \frac{\partial C}{\partial x}+h E_{x y} \frac{\partial C}{\partial y}\right) \\
& +\frac{\partial}{\partial y}\left(h E_{y x} \frac{\partial C}{\partial x}+h E_{y y} \frac{\partial C}{\partial y}\right)
\end{aligned}
$$

where $C$ is the depth-averaged solute concentration $\left(\mathrm{kg} \mathrm{m}^{-3}\right), U, V$ are the vertically integrated velocity components $\left(\mathrm{m} \mathrm{s}^{-1}\right)$ in the $x$-, $y$-directions respectively. The coefficients $E_{i j}\left(\mathrm{~m}^{2} \mathrm{~s}^{-1}\right), i, j=x, y$, account for both turbulent diffusion and shear dispersion due to vertical velocity gradients, and are related to the transverse diffusivity, $E_{T}$, and the longitudinal dispersion coefficient, $E_{L}$, by the following equations (Arega and Sanders, 2004):

$$
\begin{aligned}
& E_{x x}=E_{L}+\left(E_{L}-E_{T}\right) \frac{U^{2}}{U^{2}+V^{2}} \\
& E_{x y}=E_{y x}=\left(E_{L}-E_{T}\right) \frac{U V}{U^{2}+V^{2}} \\
& E_{y y}=E_{T}+\left(E_{L}-E_{T}\right) \frac{V^{2}}{U^{2}+V^{2}}
\end{aligned}
$$

An expression for the transverse diffusivity for flows through emergent vegetation was proposed by Nepf (1999). This is written in nondimensional form as

$$
\frac{E_{T}}{U d}=\alpha_{h}\left[c_{v D} a d\right]^{1 / 3}+\frac{\beta^{2}}{2} a d
$$

where $\alpha_{h}$ and $\beta$ are $O(1)$-scale factors. The first and the second term on the right-hand side of Eq. (12) represent the effect of turbulent diffusion and mechanical dispersion, respectively. Nepf (1999) compared the predictions of Eq. (12) with experimental data from laboratory experiments in the range $R e_{d}=400-2000$ and field experiments in the range $R e_{d}=300-600$, and found good agreement for $\alpha_{h}=0.81$ and $\beta=1$.

The expression of the turbulent diffusivity in Eq. (12) is based on the assumption that all the energy extracted from the mean flow through stems is converted into turbulent kinetic energy. This assumption is limited for $R e_{d}<200$, when the effect of viscous drag becomes significant. As experimentally confirmed by Nepf (1999) for sufficiently small stem densities, ad $<0.01$, mechanical dispersion is small compared to turbulent diffusion and the second term on the right-hand side of (12) can be neglected. Similar experiments conducted for stem Reynolds numbers in the range between 90 and 2000 (typical value $\approx 200-300$ ) show that this is not the case for the lower end of the range (low stem Reynolds numbers), for which mechanical diffusion appear to be the only important mechanism. However, Lightbody and Nepf (2006) used this assumption as a first approximation to determine the longitudinal dispersion coefficient $E_{L}$ in field experiments with flow speeds through marsh canopy varying from 0.1 to $24 \mathrm{cms}^{-1}$ $\left(R e_{d}=2--360\right)$. The proposed longitudinal dispersion coefficient, $E_{L}$, is written in nondimensional form as a combination of the stem-scale and the depth-scale dispersion process:

$\frac{E_{L}}{U d}=\frac{1}{2} c_{v D}^{3 / 2}+\frac{U h}{D_{z}} \Gamma$

where $D_{z}=\alpha_{v}\left[c_{v D} a d\right]^{1 / 3} U d$ is the vertical turbulent diffusion coefficient, $\alpha_{v}$ is a scale factor, and $\Gamma$ is the nondimensional velocity shape factor. The simulations in this study were performed for $\alpha_{v}=0.1$, which fits within the range of values reported by Nepf (2004) and Lightbody and Nepf (2006).

The first term of (13) accounts for the stem-scale longitudinal dispersion process, whereas the second term accounts for the dispersion induced by vertical velocity gradients. As noted by Lightbody and Nepf (2006), the first term of (13) is typically much smaller than the second term, and can be neglected. For the range of stem Reynolds numbers investigated in this work it is reasonable to consider only the first term of Eq. (12) and only the second term of Eq. (13).

\subsection{Residence time distributions}

The physical and chemical transformations of dissolved solutes in a wetland depend on the time spent by a particle in the vegetated zones. The residence time of a solute particle can vary to a wide degree due to different flow paths, velocity gradients and hydraulic short-circuits (Somes et al., 1999), making a statistical description in terms of probability distributions more appropriate for analyzing the problem (Somes et al., 1999; Kadlec and Wallace, 2009). Hydraulic RTDs provide a measure of the variability of the detention time and can be a valuable tool for assessing the efficiency of contaminant removal. By using a two-dimensional depth-averaged hydrodynamic model in combination with a solute transport model, it is possible to numerically derive the RTDs as a function of the system variables. Other studies have used a similar approach to characterize the hydraulic response of a wetland (Wörman and Kronnäs, 2005).

The mass outflow, $\dot{M}\left(\mathrm{~kg} \mathrm{~s}^{-1}\right)$, is given by the temporal convolution between the mass inflow, $\dot{M}_{\text {in }}$, and the probability density function of the residence time, $\phi(t)$ :

$\dot{M}_{\text {out }}=\left(\phi * \dot{M}_{\text {in }}\right)(t)=\int_{0}^{t} \phi(\tau) \dot{M}_{\text {in }}(t-\tau) \mathrm{d} \tau$

Eq. (14) expresses the fact that a fluid particle entering the system at time $t-\tau$ flows out at time $t$ with probability $\phi(\tau) d \tau$. In this work the expression "residence time distribution" (RTD) is used to denote the probability density function of the residence time, $\phi(t)$.

In general, the mass inflow $\dot{M}_{\text {in }}$ can be time-dependent, and can be written as the product of the input concentration $C_{i n}(t)\left(\mathrm{kg} \mathrm{m}^{-3}\right)$ and the inflow discharge $Q_{\text {in }}(t)\left(\mathrm{m}^{3} \mathrm{~s}^{-1}\right)$, hence $\dot{M}_{\text {in }}=C_{\text {in }}(t) Q_{\text {in }}(t)$. Under the assumption of steady-state flow, $Q_{\text {in }}(t)=\bar{Q}$ and assuming a constant concentration at the inlet, $\bar{C}_{i n}$, Eq. (14) can be arranged in the form:

$\frac{\dot{M}_{\text {out }}}{\overline{\bar{C}}_{\text {in }} \bar{Q}}=\int_{0}^{t} \phi(\tau) \mathrm{d} \tau$

The right-hand side of Eq. (15) represents the cumulative distribution function of the wetland hydraulic residence time, denoted by $\Phi(t)$. Under steady flow conditions, the water inflow equals the water outflow, therefore $\dot{M}_{\text {out }}=C_{\text {out }}(t) \bar{Q}$. Eq. (15) then becomes:

$\frac{C_{\text {out }}(t)}{\bar{C}_{\text {in }}}=\int_{0}^{t} \phi(\tau) \mathrm{d} \tau=\Phi(t)$ 
and hence:

$\phi(t)=\frac{\mathrm{d} \Phi(t)}{\mathrm{d} t}=\frac{\mathrm{d}}{\mathrm{d} t}\left(\frac{C_{\text {out }}(t)}{\bar{C}_{\text {in }}}\right)$

Eq. (17) provides the link between solute breakthrough curves and RTDs. In particular, if a constant unitary concentration, $\bar{C}_{\text {in }}=1$, is imposed as a boundary condition at the inlet, the hydraulic RTD can be obtained by numerically differentiating the output concentration $C_{\text {out }}(t)$ with respect to time.

\subsection{Model application}

The flow domain considered in this work is given by a rectangular wetland with length $L=200 \mathrm{~m}$, width $B=50 \mathrm{~m}$, and constant bed elevation (Fig. 1). The choice of a zero bed slope is supported by the evidence that in many natural wetlands the bed elevation does not vary significantly in the streamwise direction, and the effect of bed slope can often be neglected (Wörman and Kronnäs, 2005; Wu, 2007). The flow domain is characterized by a main flow channel surrounded by vegetated zones on both sides. The channel follows the center line of the wetlands and has a uniform width $b$. The wetland inlet and outlet coincide with the end sections of the main channel. Two different values of the channel width were considered in this work: $b=5 \mathrm{~m}$ and $b=10 \mathrm{~m}$.

For the flow Eqs. (1)-(3), the boundary conditions are given by the inflow at the inlet, $Q=0.5 \mathrm{~m}^{3} \mathrm{~s}^{-1}$, and the water depth at the outlet, $h=0.5 \mathrm{~m}$. For the solute transport equation, the boundary conditions are given by a constant unitary concentration at the inlet, $C=1$, an open boundary condition at the outlet, and the no-flux condition on the remaining part of the flow boundary. The equations are solved via a finite element method using COMSOL Multiphysics ${ }^{\circledR}$ with quadratic shape functions. The computational grid is made of approximately 150000 triangular elements, with higher spatial resolution near the inlet and the outlet, and a maximum element size of $2 \mathrm{~m}$.

Simulations of the hydraulic RTD are performed in three steps: first, the steady-state flow field is derived by solving the flow Eqs. (1)-(3); second, the transport equation is solved using the previously calculated flow field until the concentration at the outlet becomes constant; finally, the average concentration at the outlet is calculated as a function of time, and the hydraulic RTD is derived by numerical differentiation of the output concentration according to (17).

A uniform value of the Manning's roughness coefficient $f=0.02 \mathrm{~m}^{-1 / 3} \mathrm{~s}$ (usually associated with bare soil) was assumed to represent the bottom flow resistance, whereas a sequence of increasing vegetation densities were imposed for the vegetative resistance. No friction was considered on the lateral walls of the wetland domain.
In the simulations, the average vegetation density of the whole wetland,

$\bar{n}=\frac{n_{2}(B-b)+n_{1} b}{B}$

was kept constant and equal to 650 stems $/ \mathrm{m}^{2}$. In Eq. (18), B denotes the wetland width, $b$ is the MFC width and $n_{i}, i=1,2$, are the vegetation densities in the MFC and the LVZs, respectively. Starting from an initial homogeneous configuration with $n_{1}=n_{2}=\bar{n}$, a sequence of decreasing vegetation densities was imposed in the main channel, varying from $n_{1}=650 \mathrm{stems} / \mathrm{m}^{2}$ down to 50 stems $/ \mathrm{m}^{2}$. The resulting vegetation density in the lateral zones was then calculated from Eq. (18) by keeping $\bar{n}$ constant and solving for $n_{2}$. This allowed to analyze the statistics of the residence time for a range of degrees of channelization while keeping the average vegetation density as constant. Ten density ratios $n^{*}=n_{1} / n_{2}$ were considered for each width ratio $b^{*}=b / B$. Note that the parameter $n^{*}$ represents the degree of uniformity of the vegetation density in the wetland, which increases as the degree of flow channelization decreases, and is equal to 1 when the vegetation density in the MFC is the same as in the LVZs. In this latter case, there is no real distinction between MFC and LVZs.

\section{1-D solute transport model}

In the two-dimensional model presented in the previous section, the hydraulic RTDs are determined in three steps: first, the 2-D depth-averaged flow equations are solved to derive the steady-state velocity field; second, the 2-D depth-averaged transport equation is solved for a continuous input resulting in a concentration field as a function of time; finally, the RTD is derived by calculating the derivative of the average concentration at the outlet according to (17). The complexity of such a modeling process can be substantially reduced if a parameterization of the RTDs is available in which the model parameters can be linked to physical characteristics of the system. One-dimensional models are generally easier to calibrate and more suitable for inverse-modeling using tracer tests (e.g. Keefe et al., 2004), especially when a closed-form solution of the underlying 1-D equations can be derived analytically. A parameterization of the hydraulic RTDs is presented here, which extends the one-dimensional residence time formulation proposed by Marion and Zaramella (2005) and Marion et al. (2008) by introducing two main transport domains.

In order to represent the effect of the differential transport in the MFC and the LVZs, the overall RTD is expressed as a weighted sum of two residence time distributions individually describing the residence time statistics in the MFC and in the LVZs. The overall RTD in a wetland segment of length $x$ is therefore written as follows:
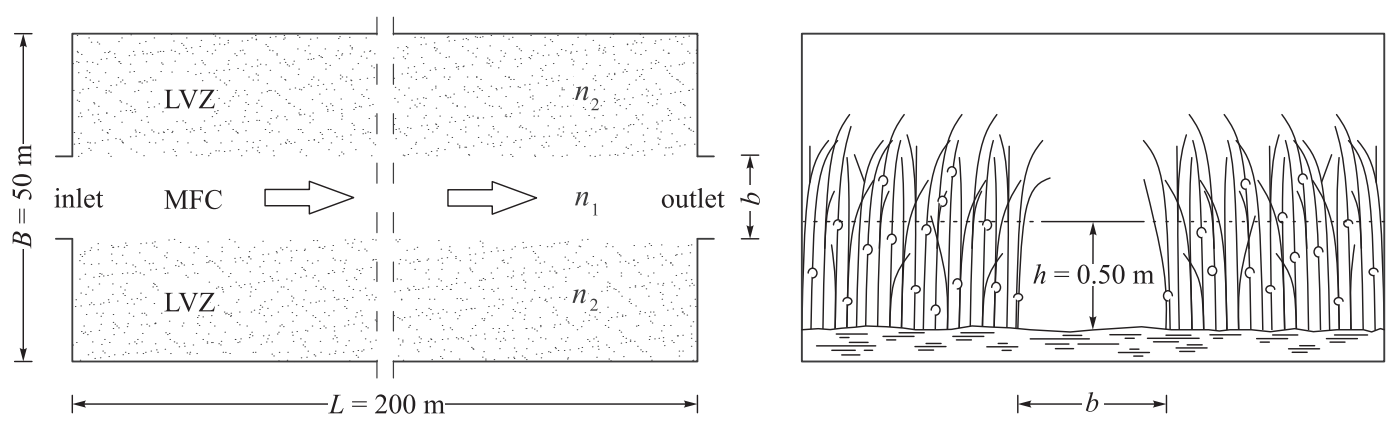

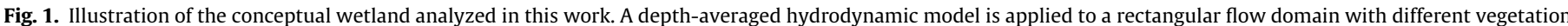

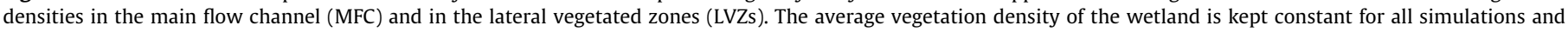
different combinations of discharge and main channel widths are investigated. 

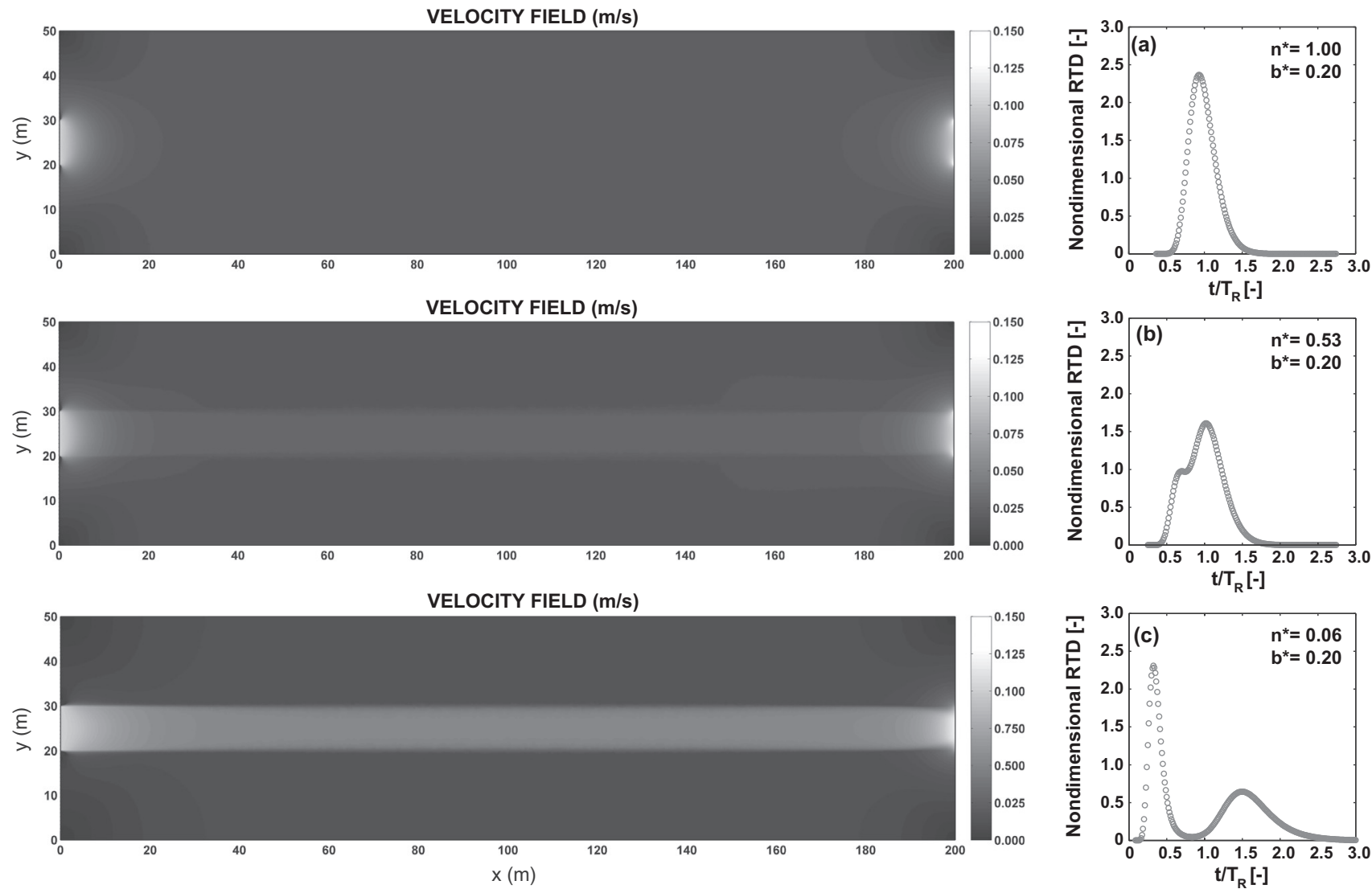

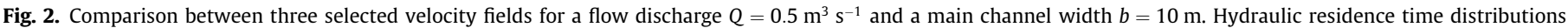

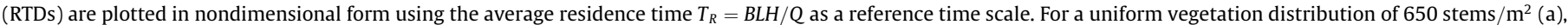

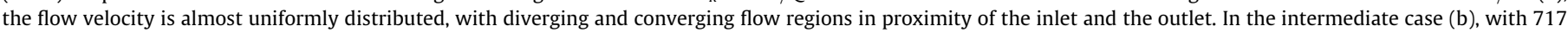

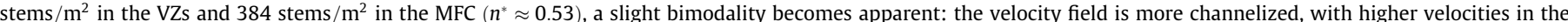

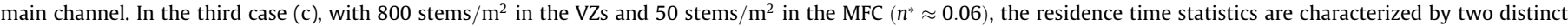
timescales, associated with the faster transport in the MFC and the slower transport in the LVZs, respectively. The result is a pronounced bimodality of the RTD.

$\phi(t ; x)=w_{1} r_{1}(t ; x)+\left(1-w_{1}\right) r_{2}(t ; x)$

where $w_{1}$ is a weight parameter $(-)$ and $r_{1}$ and $r_{2}$ are the hydraulic residence time distributions in the MFC and in the LVZs, respectively. In the model application presented in this work the variable $x$ is replaced by the longitudinal extension of the wetland, $L$, since the focus of the analysis is on the residence time statistics in the whole wetland. However, the dependence on the coordinate $x$ is maintained in Eq. (19) for sake of generality.

The functional form of the individual RTDs, $r_{1}$ and $r_{2}$, is derived from the solution of the advection-dispersion equation for a mass pulse at $x=0$, and is given by:

$r_{i}(t ; x)=\frac{x}{\sqrt{4 \pi K_{i} t^{3}}} \exp \left[-\frac{\left(x-U_{i} t\right)^{2}}{4 K_{i} t}\right]$

where the subscript $i$ takes the value 1 for the MFC, and 2 for the LVZs. For a reactive tracer with first-order decay rate constant $\lambda$ $\left(\mathrm{s}^{-1}\right)$, Eq. (20) is modified as follows:

$r_{i}(t ; x)=\frac{x}{\sqrt{4 \pi K_{i} t^{3}}} \exp \left[-\frac{\left(x-U_{i} t\right)^{2}}{4 K_{i} t}-\lambda_{i} t\right]$

The model defined by Eqs. (19) and (20) depends on five parameters characterizing the transport dynamics of a passive tracer in a channelized wetland, namely, the average flow velocities $U_{1}$ and $U_{2}$, the longitudinal dispersion coefficients, $K_{1}$ and $K_{2}$, and the weight parameter $w_{1}$. If the flow discharges are denoted by $Q_{1}$ and $Q_{2}$ and the flow cross-sectional areas are denoted by $A_{1}$ and
$A_{2}$, then $U_{1}=Q_{1} / A_{1}$ and $U_{2}=Q_{2} / A_{2}$. The weight factor $w_{1}$ can then be calculated as the fraction of the total discharge flowing through the main channel, $w_{1}=Q_{1} / Q$, where $Q=Q_{1}+Q_{2}$ is the total discharge.

The above-described model was implemented as an extension of the software STIR (Solute Transport In Rivers), which provides an expandable modeling framework and a set of optimization routines for model calibration. ${ }^{1}$ This particular extension is referred to as STIR-DTD, where the acronym DTD stands for Double Transport Domain. Although in this study the transport dynamics in the MFC and in the LVZs is represented as a purely advection-dispersion process, the software allows to incorporate additional retention processes via specific RTDs.

The capability of the model to reproduce the observed RTDs was analyzed by calibrating the model against the results of the twodimensional simulations. The RTDs resulting from Eqs. (19) and (20) were fitted to the RTDs generated according to Section 2.3 and the behavior of the parameters was analyzed as a function of the degree of channelization. The calibration parameters are given by the velocities $U_{1}, U_{2}$, and the dispersion coefficients $K_{1}$ and $K_{2}$, whereas the weight factor $w_{1}$ was imposed using the definition $w_{1}=Q_{1} / Q$ and the flow discharge $Q_{1}$ calculated from the hydrodynamic model.

Whilst the parameter calibration procedure provides a way to assess the suitability of the functional form (19) and (20) to

\footnotetext{
1 The software is available for download at www.wetengineering.com.
} 
represent the numerically simulated RTDs, a direct modeling approach may be preferable in predictive studies even though a certain degree of approximation is involved. Here, an approximate relationship is derived for the discharges $Q_{1}$ and $Q_{2}$ that can be used to calculate the parameters $U_{1}, U_{2}$ and $w_{1}$. The relationship is based on Manning's equation, $U=f_{e q}^{-1} R_{H}^{2 / 3} S^{1 / 2}$, in which $R_{H}$ is the hydraulic radius $(\mathrm{m}), S$ the slope of the energy line (-), and $f_{e q}$ is an equivalent roughness coefficient representing the flow resistance due to vegetation and bed friction. The Manning's roughness coefficient, $f_{e q}$, is linked to the sum of the bed and vegetation shear stress, $\tau=\tau_{b}+\tau_{v}$, by the relationship

$f_{e q}=\frac{1}{U} R_{H}^{2 / 3}\left(\frac{\tau}{\gamma R_{H}}\right)^{1 / 2}=\frac{1}{U} R_{H}^{1 / 6}\left(\frac{\tau}{\gamma}\right)^{1 / 2}$

where the equation $\tau=\gamma R_{H} S$ was used to link the total shear stress to the energy slope, $S$. If the hydraulic radius is approximated with the water depth, $h$, the equivalent Manning's roughness coefficient for fully emergent vegetation becomes:

$f_{e q}=\frac{1}{g^{1 / 2}}\left(f^{2} g+\frac{3 v h^{-2 / 3}}{U}+\frac{5 v h^{4 / 3}}{U} n+\frac{d h^{4 / 3}}{2} n\right)^{1 / 2}$

The first two terms in parenthesis are associated with the bed roughness, whereas the last two terms represent the contribution to the shear stress due to vegetation. Under the flow conditions analyzed in this work, the first two terms are generally much smaller than the others. Also, with exception for the lower end of the range of Reynolds numbers, the third term can be considered small compared to the fourth. Under these assumptions, the equivalent Manning's roughness coefficient can be written as
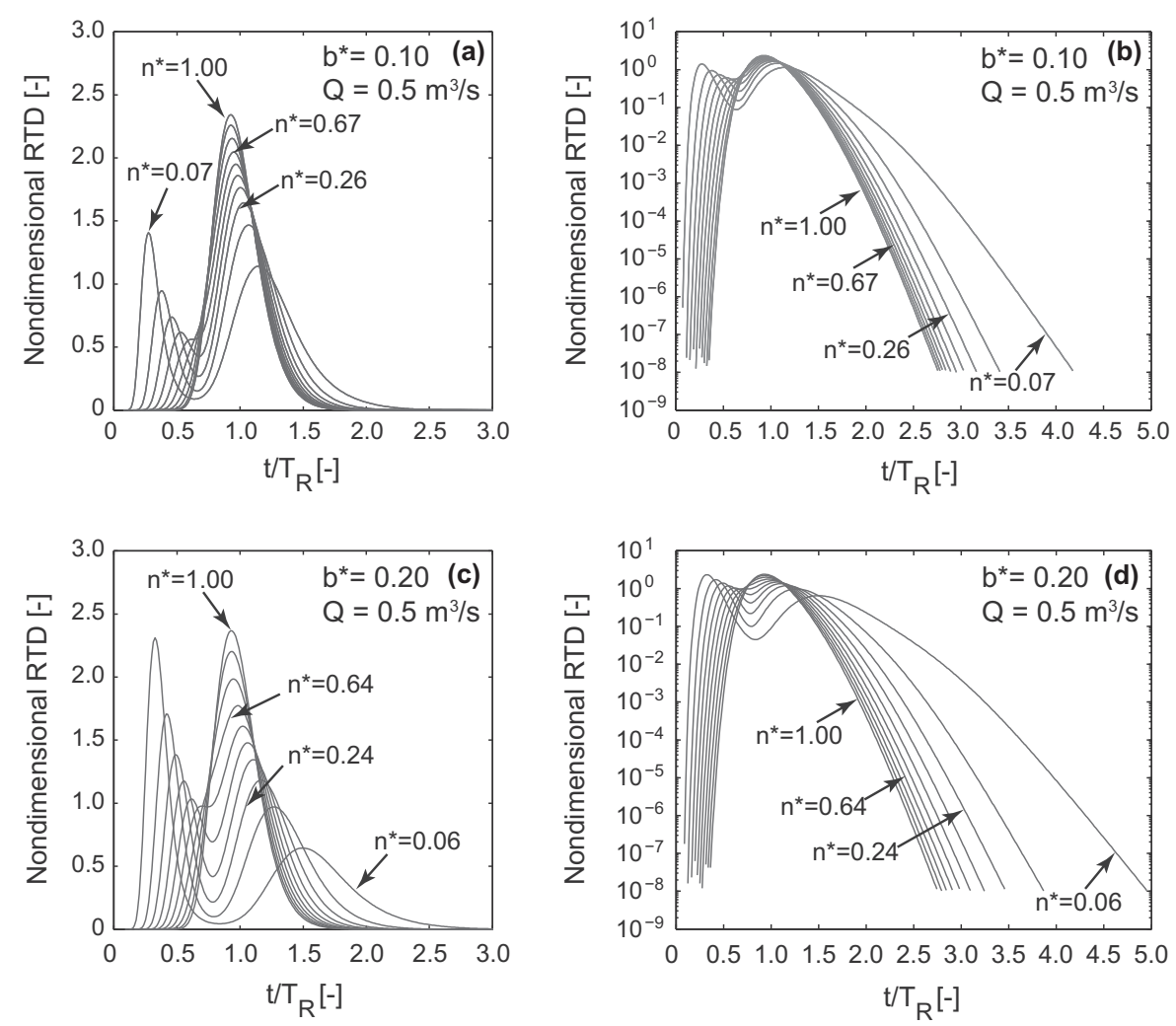

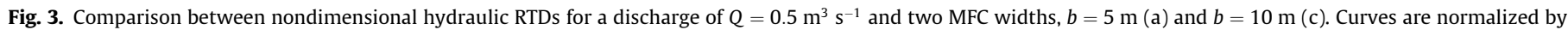

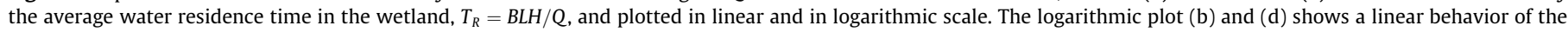
curves at longer times. 
predictions from (28) and (29), and an attempt is made to clarify the parametric dependence of the dispersion coefficients $K_{1}, K_{2}$ as a function of the density ratio, $n^{*}$.

\section{Results and discussion}

Fig. 2 shows the effect of different vegetation densities on the velocity field. For a homogeneous roughness distribution, the velocity profile becomes approximately uniform at a distance of $20-25 \mathrm{~m}$ from the wetland inlet. The most significant velocity gradients are located in proximity of the inlet and the outlet section, with higher velocities in the center line and significantly smaller velocities at the corners (Fig. 2a). As the difference between stem density in the main channel and in the lateral banks increases, the flow is increasingly confined in the main channel and a first evidence of the bimodal behavior appears in the RTD (Fig. 2b). In the most channelized case (Fig. 2c), the hydraulic RTD shows an evident bimodality, indicating that mass transport is characterized by two distinct time scales associated with the transport in the main flow channel (MFC) and in the lateral vegetated zones (LVZs). The development of a clear bimodality as $n^{*}$ decreases supports the decomposition of the overall RTD into two components according to Eq. (19).

A comparison of the RTDs is presented in Fig. 3 for a constant flow discharge $Q=0.5 \mathrm{~m}^{3} \mathrm{~s}^{-1}$ and for two different values of the parameter $b^{*}=b / B$. In the figure, the residence time is normalized by the mean hydraulic residence time in the wetland, defined as $T_{R}=B L H / Q$, where $H$ is the average water depth $(\mathrm{m})$ and $L$ is the wetland length $(\mathrm{m})$. When the RTDs are plotted in a semilogarithmic scale (Fig. 3b and d), it becomes apparent that the RTDs decay exponentially and the slope of the tails depends on the ratio of vegetation density, $n^{*}$. As $n^{*}$ decreases, the slope of the tails decreases
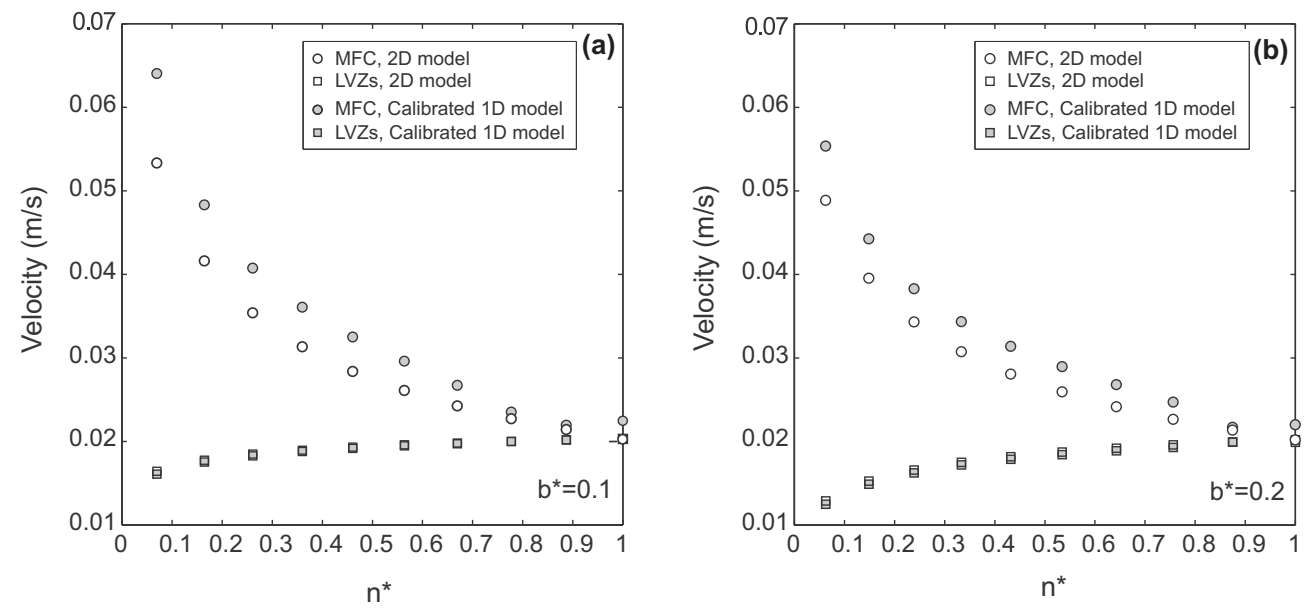

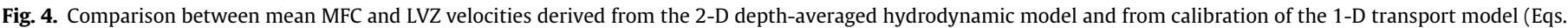
(19) and (20)). Results are plotted for $b^{*}=0.1$ (a) and $b^{*}=0.2$ (b).

Table 1

Best-fit model parameters for $Q=0.5 \mathrm{~m}^{3} \mathrm{~s}^{-1}$ and main channel width $b=5 \mathrm{~m}$.

\begin{tabular}{|c|c|c|c|c|c|c|c|c|c|c|}
\hline$n^{*}(-)$ & 1.00 & 0.887 & 0.777 & 0.669 & 0.564 & 0.461 & 0.360 & 0.261 & 0.164 & 0.070 \\
\hline$w_{1}(-)$ & 0.101 & 0.107 & 0.114 & 0.121 & 0.130 & 0.142 & 0.157 & 0.177 & 0.208 & 0.267 \\
\hline$K_{1}\left(\times 10^{-2} \mathrm{~m}^{2} \mathrm{~s}^{-1}\right)$ & 3.56 & 4.46 & 9.58 & 10.4 & 10.3 & 11.2 & 12.8 & 17.0 & 25.7 & 47.8 \\
\hline$K_{2}\left(\times 10^{-2} \mathrm{~m}^{2} \mathrm{~s}^{-1}\right)$ & 6.88 & 7.43 & 7.14 & 6.82 & 6.62 & 6.68 & 6.72 & 6.78 & 6.96 & 7.83 \\
\hline$U_{1}\left(\times 10^{-2} \mathrm{~m} \mathrm{~s}^{-1}\right)$ & 2.25 & 2.20 & 2.35 & 2.67 & 2.96 & 3.25 & 3.61 & 4.08 & 4.83 & 6.41 \\
\hline$U_{2}\left(\times 10^{-2} \mathrm{~m} \mathrm{~s}^{-1}\right)$ & 2.02 & 2.02 & 2.00 & 1.97 & 1.95 & 1.92 & 1.88 & 1.83 & 1.75 & 1.61 \\
\hline $\mathrm{T}_{1}\left(\times 10^{3} \mathrm{~s}\right)$ & 8.90 & 9.11 & 8.50 & 7.48 & 6.76 & 6.15 & 5.55 & 4.91 & 4.14 & 3.12 \\
\hline $\mathrm{T}_{2}\left(\times 10^{3} \mathrm{~s}\right)$ & 9.92 & 9.92 & 10.0 & 10.1 & 10.3 & 10.4 & 10.6 & 10.9 & 11.4 & 12.4 \\
\hline $\mathrm{Pe}_{1}\left(\times 10^{4}\right)$ & 2.10 & 2.17 & 2.27 & 2.40 & 2.54 & 2.72 & 2.96 & 3.29 & 3.85 & 5.15 \\
\hline $\mathrm{Pe}_{2}\left(\times 10^{4}\right)$ & 9.38 & 9.35 & 9.31 & 9.26 & 9.22 & 9.18 & 9.13 & 9.08 & 9.02 & 8.93 \\
\hline
\end{tabular}

Table 2

Best-fit model parameters for $Q=0.5 \mathrm{~m}^{3} \mathrm{~s}^{-1}$ and main channel width $b=10 \mathrm{~m}$.

\begin{tabular}{|c|c|c|c|c|c|c|c|c|c|c|}
\hline$n^{*}(-)$ & 1.00 & 0.875 & 0.756 & 0.643 & 0.535 & 0.432 & 0.333 & 0.239 & 0.149 & 0.0625 \\
\hline$w_{1}(\%)$ & 0.202 & 0.213 & 0.226 & 0.241 & 0.259 & 0.280 & 0.307 & 0.343 & 0.395 & 0.489 \\
\hline$K_{1}\left(\times 10^{-2} \mathrm{~m}^{2} \mathrm{~s}^{-1}\right)$ & 4.38 & 6.44 & 7.63 & 8.04 & 8.70 & 9.77 & 11.7 & 15.1 & 21.0 & 35.8 \\
\hline$K_{2}\left(\times 10^{-2} \mathrm{~m}^{2} \mathrm{~s}^{-1}\right)$ & 6.67 & 7.41 & 6.44 & 6.10 & 5.94 & 5.89 & 5.84 & 5.75 & 5.63 & 5.45 \\
\hline$U_{1}\left(\times 10^{-2} \mathrm{~m} \mathrm{~s}^{-1}\right)$ & 2.20 & 2.17 & 2.47 & 2.68 & 2.90 & 3.14 & 3.44 & 3.83 & 4.43 & 5.54 \\
\hline$U_{2}\left(\times 10^{-2} \mathrm{~m} \mathrm{~s}^{-1}\right)$ & 1.99 & 1.99 & 1.93 & 1.89 & 1.84 & 1.79 & 1.72 & 1.62 & 1.49 & 1.25 \\
\hline $\mathrm{T}_{1}\left(\times 10^{3} \mathrm{~s}\right)$ & 9.08 & 9.21 & 8.08 & 7.45 & 6.90 & 6.37 & 5.82 & 5.22 & 4.52 & 3.61 \\
\hline $\mathrm{T}_{2}\left(\times 10^{3} \mathrm{~s}\right)$ & 10.0 & 10.0 & 10.4 & 10.6 & 10.9 & 11.2 & 11.6 & 12.3 & 13.4 & 16.0 \\
\hline $\mathrm{Pe}_{1}\left(\times 10^{4}\right)$ & 4.19 & 4.34 & 4.56 & 4.79 & 5.08 & 5.43 & 5.90 & 6.57 & 7.68 & 10.3 \\
\hline $\mathrm{Pe}_{2}\left(\times 10^{4}\right)$ & 8.33 & 8.26 & 8.18 & 8.10 & 8.02 & 7.59 & 7.86 & 7.77 & 7.66 & 7.49 \\
\hline
\end{tabular}



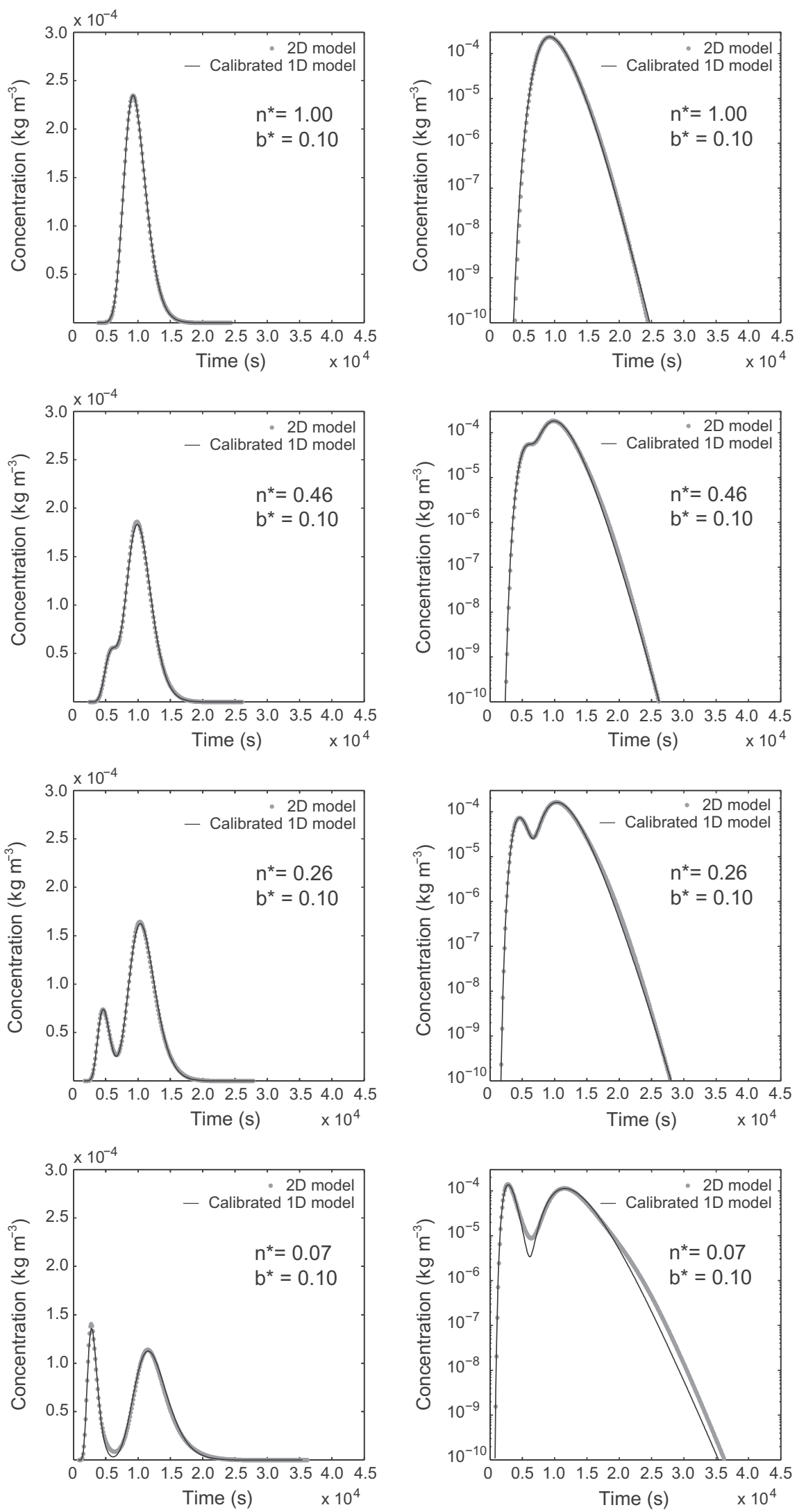

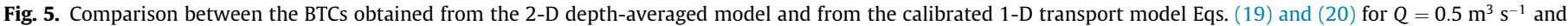
$b=5 \mathrm{~m}$. 
and the distributions resemble more closely the solution of a conventional advection-dispersion equation. The shape of the RTDs is also affected by the width of the main channel. For a larger width, $b^{*}=0.2$, the RTDs decay more slowly than for $b^{*}=0.1$, indicating a slower transport in the LVZs. Also, for $b^{*}=0.2$ the peak of the faster component is higher than for $b^{*}=0.1$, due to the higher discharge in the MFC (Fig. 3a and $c$ ).

As the ratio $n^{*}=n_{1} / n_{2}$ decreases, the mean velocity in the lateral vegetated zones decreases whereas the mean velocity in the main channel increases. This behavior is shown in Fig. 4 and confirmed by the pattern of the mean residence times in each zone as a function of the density ratio, $n^{*}$ (Tables 1 and 2). Fig. 4 also shows a comparison between the mean velocity derived from the 2-D depth-averaged model and from calibration of the 1-D transport model expressed by Eqs. (19) and (20). The former is obtained by calculating the cross-sectional average of the 2-D depth-averaged velocity field for the MFC and the LVZs, whereas the latter is derived by calibrating the 1-D model against the BTCs obtained from the 2-D transport model.

For decreasing values of $n^{*}$ the time scale of transport in the MFC, $T_{1}=L / U_{1}$, decreases and the time scale of the transport in the LVZs, $T_{2}=L / U_{2}$, increases. The fraction $w_{1}=Q_{1} / Q$ of the total discharge flowing through the main channel, calculated in the central region of the domain where the flow is not affected by inlet and outlet effects, is shown in Tables 1 and 2. The value of $w_{1}$ for a channel width $b=5 \mathrm{~m}$ is approximately double the value for $b=10 \mathrm{~m}$, whereas $w_{1}=1$ for the limit case of $b=B$. Fig. 5 shows a comparison between the breakthrough curves generated with the 2-D model and the curves generated with the calibrated onedimensional model. As explained in the previous section, in the calibration, the parameter $w_{1}$ was imposed using the flow discharge $Q_{1}$ calculated from the 2-D simulations, whereas the parameters $U_{1}, U_{2}, K_{1}$ and $K_{2}$ were optimized to obtain a best-fit with the 2-D model results. A good agreement between the curves is found both in linear and in logarithmic scale. The use of an advection-dispersion model for the two transport components leads to a satisfactory representation of the RTDs, both in presence and absence of a clear bimodality. The behavior of the tails is also well represented, with only a slight deviation in the most channelized case. The model is therefore capable to represent the residence time statistics with good approximation, matching the main time scales and the variance of the RTDs.

The conceptual model expressed by Eqs. (28) and (29) linking the weight $w_{1}$ to the channel width, $b^{*}$, and the vegetation density ratio, $n^{*}$, shows a good agreement with the flow discharges calculated in the 2-D simulations. As shown in Fig. 6, the model appears to slightly overestimate the discharge flowing in the MFC (and consequently underestimate the discharge in the LVZs), especially for smaller values of $n^{*}$. In this case, the vegetation density in the main channel is lower and the velocity higher, making the magnitude of the first term of Eq. (23) comparable to the fourth term, which was neglected in the derivation of (28) and (29). This term should be taken into account if a higher accuracy is desired. However, the approximation provided by Eqs. (28) and (29) appears to be quite satisfactory to determine the value of the weight factor $w_{1}$, as demonstrated by the graph in Fig. 6 .

The values of the Peclet number for the main channel, $P e_{1}=U_{1} b / E_{T, 1}$, and the lateral vegetated zones, $P e_{2}=U_{2}(B-b) /$ $2 E_{T, 2}$, calculated using the transverse diffusion coefficient (12), are reported in Tables 1 and 2, respectively. The values indicate that the transport process is dominated by advection both in the MFC and in the LVZs. In particular, it is interesting to note that the nondimensional longitudinal dispersion coefficients, defined as $K_{i}^{*}=K_{i} / E_{T, i}$, are found to be proportional to the square of the Peclet number $P e_{i}^{2}$. This means that the ratio $K_{i}^{*} / \mathrm{Pe}^{2}$ is approximately constant as the density ratio $n^{*}$ varies. Deviations from a

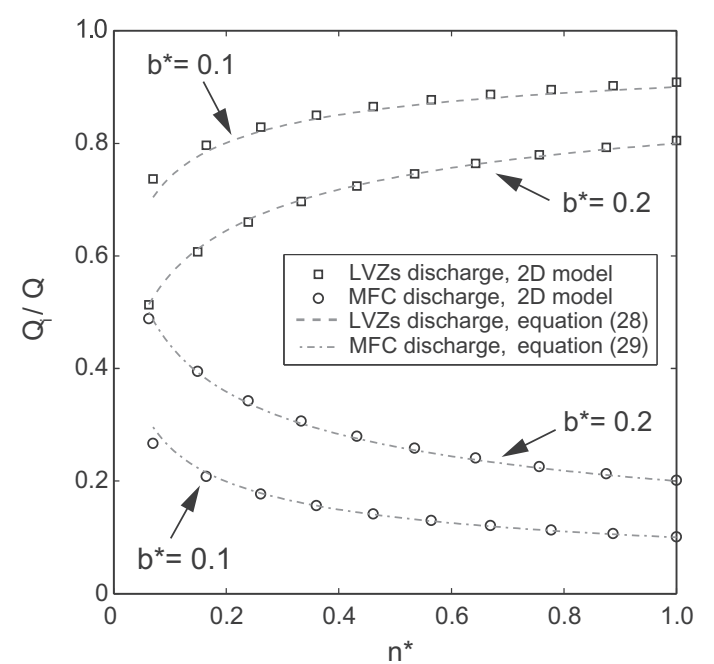

Fig. 6. Comparison between discharges calculated with the 2-D model depthaveraged model and Eqs. (28) and (29). Results are plotted for $b^{*}=0.1$ and $b^{*}=0.2$.

constant value are observed for density ratios close to one (i.e. $n^{*} \approx 1$ ) for which the bimodality of the RTDs is much less pronounced, making the parameter estimation procedure unable to distinguish between the two transport components.

Overall, the parameterization of the RTDs expressed by Eqs. (19) and (20) reproduces satisfactorily the shape of the simulated RTDs, and the approximate relationships (28) and (29) provide a reliable estimate of the flow discharges in the MFC and the LVZs. Although the parametric dependence of the dispersion coefficients $K_{1}$ and $K_{2}$ is not fully resolved, results show that the ratios $K_{i}^{*} / \mathrm{Pe}^{2}$ are independent of $n^{*}$ and depend only on the nondimensional channel width $b^{*}$ (Fig. 7).

To the best of our knowledge, this is the first study that systematically analyzes the effect of vegetation density on the behavior of the hydraulic RTDs in a channelized wetland. The parameterization of the RTDs suggested in this work has potential application to both natural and constructed wetlands characterized by a main flow channel and later zones with emergent vegetation. Although the analysis presented here is focused on passive tracers, the model can also be applied to reactive solutes by using Eq. (19) in combination with (21) for first-order decay reactions. Further study is needed to understand the behavior of the RTDs and the resulting wetland performance in more complex configurations.

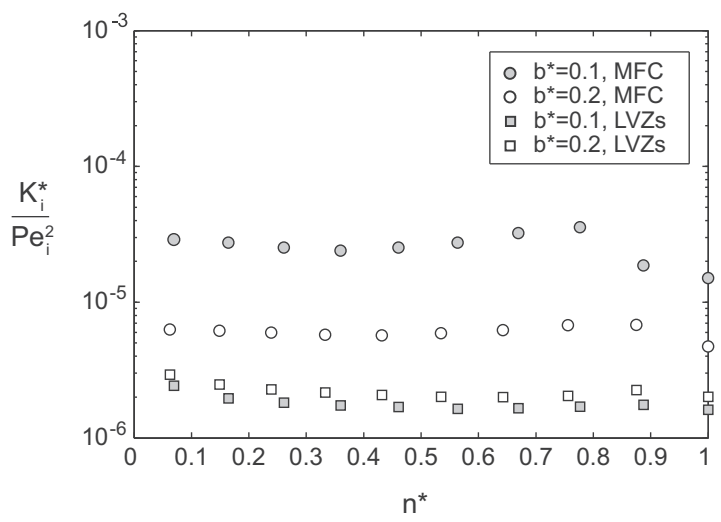

Fig. 7. Behavior of the ratio $K_{i}^{*} / P e_{i}^{2}$ in each zone. The nondimensional groups are calculated using the transverse diffusivity defined by Eq. (12). 


\section{Conclusions}

A two-dimensional depth-averaged hydrodynamic model coupled with a solute transport model was used to derive the hydraulic residence time distribution in a conceptual wetland characterized by a main flow channel and lateral vegetated zones. Results show that the partition of the flow between the main channel and the vegetated zones leads to a bimodal behavior of the hydraulic RTD. The RTD was parameterized as a weighted average of two RTDs resulting from advective-diffusive transport along two one-dimensional domains. Although the model can be extended to account for additional retention processes, the use of a conventional advectiondispersion model for each transport domain was shown to be sufficient to adequately reproduce the observed bimodality, with a reasonable level of accuracy also for the tail behavior of the RTDs. The best-fit model parameters were analyzed as a function of the width of the MFC and the density ratio between the MFC and the LVZs. The position of the two concentration peaks on the time axis is linked to the average travel time in each zone, whilst the ratio between the nondimensional longitudinal dispersion coefficient and the square of the Peclet number was found to be approximately constant. Approximate analytical relationships were derived for the flow discharges in the MFC and in the LVZs, which allow to estimate part of the model parameters in a predictive way.

The analysis presented in this work retains a number of limitations due to the simplified geometry and topography of the simulated wetland. Even in the idealized case of a rectangular wetland with uniform bed elevation, the residence time statistics depend on several variables, such as the flow discharge, the wetland aspect ratio, the geometry of the main channel and the vegetation density, making the problem extremely complex to describe in a comprehensive way. This complexity is further increased by uncertainty, which arises as a consequence of spatial heterogeneities and temporal fluctuations driven by meteorological factors such as wind, temperature and rainfall. The methodology and the results presented in this work can, however, be a basis for future studies aiming to clarify the relationship between contaminant removal efficiency and design parameters of constructed wetlands for waste-water treatment.

\section{Acknowledgements}

The work of the first author was supported by the project "Progetto Dottorati di Ricerca 2009" funded by the Cassa di Risparmio di Padova e Rovigo foundation. The work of the second author was supported in part by the STandUP for Energy collaboration initiative during his stay at the Department of Civil and Architectural Engineering, Royal Institute of Technology (KTH). The authors gratefully acknowledge Prof. Gunnar Nützmann, HumboldtUniversität of Berlin, for his comments on the early draft of this work.

\section{References}

Akratos, C., Tsihrintzis, V., 2007. Effect of temperature, HRT, vegetation and porous media on removal efficiency of pilot-scale horizontal subsurface flow constructed wetlands. Ecol. Eng. 29 (2), 173-191.

Arega, F., Sanders, B.F., 2004. Dispersion model for tidal wetlands. J. Hydraul. Eng. 130 (8), 739-754.

Babarutsi, S., Ganoulis, J., Chu, V.H., 1989. Experimental investigation of shallow recirculating flows. J. Hydraul. Eng. 115 (7), 906-924.
Bencala, K.E., Walters, R.A., 1983. Simulation of solute transport in a mountain pooland-riffle stream: a transient storage model. Water Resour. Res. 19 (3), 718 724.

Bennett, C.O., Myers, J.E., 1962. Momentum, Heat, and Mass Transfer. McGraw-Hill New York.

Blevins, R.D., 2005. Forces on and stability of a cylinder in a wake. J. Offshore Mech. Arct. Eng. 127, 39-45.

Ergun, S., 1952. Fluid flow through packed columns. Chem. Eng. Prog. 48, 89-94.

Gooseff, M.N., Wondzell, S.M., Haggerty, R., Anderson, J., 2003. Comparing transient storage modeling and residence time distribution (RTD) analysis in geomorphically varied reaches in the lookout creek basin, oregon, USA. Adv. Water. Resour. 26 (9), 925-937.

Hall, B.R., Freeman, G.E., 1994. Study of hydraulic roughness in wetland vegetation takes new look at mannings n. US Army Corps Eng. Waterways Exp. Station Wetlands Res. Prog. Bull. 4, 14

Hill, R.J., Koch, D.L., Ladd, A.J.C., 2001. Moderate-reynolds-number flows in ordered and random arrays of spheres. J. Fluid. Mech. 448 (2), 243-278.

Hocking, P., 1989. Seasonal dynamics of production, and nutrient accumulation and cycling by phragmites asutralis (Cav.) trin. ex stuedel in a nutrient-enriched swamp in inland australia. i. Whole plants. Mar. Freshwater. Res. 40 (5), 421 444.

Jenkins, G.A., Greenway, M., 2005. The hydraulic efficiency of fringing versus banded vegetation in constructed wetlands. Ecol. Eng. 25 (1), 61-72.

Kadlec, R.H., 1990. Overland flow in wetlands: vegetation resistance. J. Hydraul. Eng. 116 (5), 691-706.

Kadlec, R.H., 2000. The inadequacy of first-order treatment wetland models. Ecol. Eng. 15 (1), 105-119.

Kadlec, R., Wallace, S., 2009. Treatment Wetlands. CRC.

Keefe, S.H., Barber, L.B., Runkel, R.L., Ryan, J.N., McKnight, D.M., Wass, R.D., 2004 Conservative and reactive solute transport in constructed wetlands. Water Resour. Res. 40 (1), W01201.

Lightbody, A.F., Nepf, H.M., 2006. Prediction of velocity profiles and longitudina dispersion in emergent salt marsh vegetation. Limnol. Oceanogr., 218-228.

Marion, A., Zaramella, M., 2005. A residence time model for stream-subsurface exchange of contaminants. Acta Geophys. Pol. 53 (4), 527.

Marion, A., Zaramella, M., Bottacin-Busolin, A., 2008. Solute transport in rivers with multiple storage zones: the STIR model. Water Resour. Res. 44 (10), W10406.

Martinez, C.J., Wise, W.R., 2003. Analysis of constructed treatment wetland hydraulics with the transient storage model OTIS. Ecol. Eng. 20 (3), 211-222.

Nepf, H.M., 1999. Drag, turbulence, and diffusion in flow through emergent vegetation. Water Resour. Res. 35 (2), 479-489.

Nepf, H.M., 2004. Vegetated Flow Dynamics. In: Fagherazzi, S., Marani, M., Blum, L. (Eds.), Ecogeomorphology of tidal marshes. Coast. Estuar. Stud., vol. 59. AGU, pp. 137-164.

Nepf, H.M., Sullivan, J.A., Zavistoski, R.A., 1997. A model for diffusion within emergent vegetation. Limnol. Oceanogr., 1735-1745.

Parr, T.W., 1990. Factors Affecting Reed (Phragmites Australis) Growth in UK Reed Bed Treatment Systems, vol. 67. Pergamon Press, Oxford, UK.

Persson, J., Somes, N., Wong, T., 1999. Hydraulics efficiency of constructed wetlands and ponds. Water Sci. Technol. 40 (3), 291-300.

Perucca, E., Camporeale, C., Ridolfi, L., 2009. Estimation of the dispersion coefficient in rivers with riparian vegetation. Adv. Water. Resour. 32 (1), 78-87.

Petryk, S., 1969. Drag on cylinders in open channel flow. Ph.D. thesis, Colorado State University.

Raupach, M.R., 1992. Drag and drag partition on rough surfaces. Bound.-Lay Meteorol. 60 (4), 375-395.

Runkel, R.L., Broshears, R.E., 1991. One-dimensional transport with inflow and storage (OTIS): a solute transport model for small streams. CADSWES, Center for Advanced Decision Support for Water and Environmental Systems, Department of Civil Engineering, University of Colorado.

Somes, N.L., Bishop, W.A., Wong, T.H., 1999. Numerical simulation of wetland hydrodynamics. Environ. Int. 25 (67), 773-779.

Tanino, Y., Nepf, H., 2008. Laboratory investigation of mean drag in a random array of rigid, emergent cylinders. J. Hydraul. Eng. 134 (1), 34-41.

Tanner, C., 2001. Growth and nutrient dynamics of soft-stem bulrush in constructed wetlands treating nutrient-rich wastewaters. Wetlands Ecol. Manage. 9 (1), 4973.

Tritton, D.J., 1959. Experiments on the flow past a circular cylinder at low reynolds numbers. J. Fluid. Mech. 6 (4), 547-567.

White, F.M., 1991. Viscous Fluid Flow. McGraw-Hill.

Wieselberger, C., 1921. Neuere feststellungen über die gesetze des flüssigkeits luftwiderstands. Physik. Z. 22, 321-328.

Wörman, A., Kronnäs, V., 2005. Effect of pond shape and vegetation heterogeneity on flow and treatment performance of constructed wetlands. J. Hydrol. 301 (1), $123-138$.

Wu, W., 2007. Computational River Dynamics. CRC. 